\title{
MEDIA VIDEO ANIMASI 3D SEBAGAI SALAH SATU PEMBELAJARAN
}

\author{
Renovita Sarassati ${ }^{1}$ \\ Amrullah $^{2}$ \\ Ahmad Saipullah ${ }^{3}$ \\ Mahasiswa STMIK Raharja Jurusan Teknik Informatika $a^{1,2,3}$ \\ Jl. Jendral Sudirman No. 40, Modern Cikokol, Tangerang ${ }^{1,2,3}$

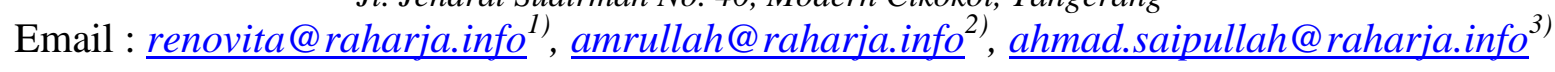

\begin{abstract}
ABSTRAK
Animasi 3D merupakan penciptaan gambar bergerak dalam ruang digital 3 dimensi. Hal ini dilakukan dengan membuat frame yang mensimulasikan masing-masing gambar, Dalam pembelajaran video animasi $3 D$ yang sangat banyak di minati masyarakat saat ini dan masa depan, sehingga media $3 D$ penting sekali dalam membuat animasi, difilmkan dengan kamera virtual, dan output-nya berupa video yang sudah di-rendering atau Realtime, jika tujuannya untuk membuat game. Animasi 3D biasanya ditampilkan dengan kecepatan lebih dari 24 frame per detik. Konsep animasi $3 D$ sendiri adalah sebuah model yang memiliki bentuk, volume, dan ruang. Animasi 3D merupakan jantung dari game dan virtual reality, tetapi biasanya animasi 3D juga digunakan dalam presentasi grafis untuk menambahkan efek visual ataupun film.
\end{abstract}

Kata Kunci: Dimensi, Video, Animasi

\begin{abstract}
$3 D$ animation is the creation of moving images in 3 dimensional digital space. This is done by creating a frame that simulates each image. In $3 D$ video animation learning is very much in the interest of today's society and the future, so the 3D media is very important in making animation, filmed with a virtual camera, and the output of the video which is already rendering or Realtime, if the goal is to create a game. 3D animations typically display at speeds in excess of 24 frames per second. The concept of 3D animation itself is a model that has the shape, volume, and space. 3D animation is at the heart of gaming and virtual reality, but usually $3 D$ animation is also used in graphical presentations to add visual effects or movies.
\end{abstract}

Keywords : Dimensions, Video, Animation

\section{PENDAHULUAN}

Memiliki koordinat X, Y, dan Z. Jika pada animasi 2D, objek hanya dapat digerakkan ke dua arah, yaitu ke kanan - kiri (X) dan atas - bawah (Y), maka berbeda dengan animasi 3D. Pada animasi 3D, objek dapat digerakkan ketiga arah, yaitu ke kanan - kiri (X), atas bawah (Y) dan depan - belakang (Z). Pada umumnya objek 3D memiliki sub objek berupa elemen-elemen pembentuk objek tersebut, yang berupa Vertex, Edge, dan Face. Vertex merupakan titik yang terletak pada koordinat X, Y, Z. Penggabungan dua Vertexakan menjadi Edge. Tiga Vertex dan Edge yang terbentuk dalam bidang permukaan berupa kurva tutup akan menghasilkan Face. Kumpulan dari Vertex, Edge, dan Face akan menjadi sebuah objek utuh yang disebut dengan Mesh.

Permodelan animasi 3D dibedakan menjadi dua, yaitu Hardsurface dan Organic. Model hardsurface adalah segala bentuk objek yang diciptakan atau dikonstruksi oleh manusia, seperti arsitektur, kendaraan, robot, dan mesin-mesin lainnya. Sedangkan 
model organic adalah subjek yang sudah secara alami ada di alam, seperti hewan, tumbuhan, batu, awan, petir, dan lain-lain.

\section{PERMASALAHAN}

Bagaimana membuat model dan animasi 3D untuk mempermudah mahasiwa dalam mempelajarinya? penulis ingin membuat animasi 3D untuk memberikan inspirasi bagi generasi muda untuk memberikan rasa percaya diri dalam berkarya dan lebih produktif untuk mengimprovisasi metode pembelajaran.

\section{LANDASAN TEORI}

Media adalah sarana untuk menyampaikan pesan atau informasi kepada publik dengan menggunakan berbagai unsur komunikasi grafis seperti teks, gambar atau foto. Sedangkan Video merupakan gabungan gambar-gambar mati yang dibaca berurutan dalam suatu waktu dengan kecepatan tertentu. Disamping itu Interior sebuah bangunan dibentuk oleh elemenelemen arsitektur dari struktur dan pembentuk ruangnya yang terdiri atas kolom, dinding, lantai, dan plafon. Elemen-elemen tersebut memberi bentuk pada bangunan, memisahkannya dengan ruang luar, dan membentuk pola tatanan ruang interior. Dan Unsur-unsur adalah alat atau bahan baku seperti cat adalah dasar-dasar untuk seorang pelukis. Promosi adalah suatu bentuk komunikasi pemasaran. Yang dimaksud dengan komunikasi pemasaran adalah aktivitas pemasaran yang berusaha menyebarkan informasi, mempengaruhi atau membujuk dan mengingatkan pasar sasaran atas perusahaan dan produknya agar bersedia menerima dan loyal pada produk yang ditawarkan perusahaan yang bersangkutan. Informasi (information) dapat didefinisikan sebagai berikut: "Informasi adalah data yang diolah menjadi bentuk yang lebih berguna dan lebih berarti bagi yang menerimannya, informasi disebut juga data yang diproses atau data yang memiliki arti." Multimedia merupakan kombinasi teks, seni, suara, gambar, animasi, dan video yang disampaikan dengan komputer atau dimanipulasi secara digital dan dapat disampaikan atau dikontrol secara interaktif. Audio visual merupakan gabungan dari dua kata yaitu audio yang berarti suara dan visual yang berarti gambar, atau dengan kata lain menjelaskan, "Audio Visual adalah alat peraga yang dapat dilihat dan didengar dalam hal ini gambar yang bergerak menimbulkan suara." Storyboard adalah sebuah teknik shooting management. Disini dibuat daftar pengambilan gambar pada setiap adegan, dan divisualisasikan dalam bentuk sketsa gambar atau storyboard jika diperlukan.

\section{Definisi 3D}

3D atau 3 Dimensi adalah sebuah objek / ruang yang memiliki panjang, lebar dan tinggi yang memiliki bentuk. 3D tidak hanya digunakan dalam matematika dan fisika saja melainkan dibidang grafis, seni, animasi, komputer dan lain-lain. Konsep tiga dimensi atau 3D menunjukkan sebuah objek atau ruang memiliki tiga dimensi geometris yang terdiri dari: kedalaman, lebar dan tinggi. Contoh tiga dimensi suatu objek / benda adalah bola, piramida atau benda spasial seperti kotak sepatu. Istilah "3D" juga (dan salah) yang digunakan (terutama bahasa Inggris) untuk menunjukkan representasi dalam grafis komputer (digital), dengan cara menghilangkan gambar stereoscopic atau gambar lain dalam pemberian bantuan, dan bahkan efek stereo sederhana, yang secara konstruksi membuat efek 2D (dalam perhitungan proyeksi perspektif, shading) Karakteristik 3D Mengacu pada tiga dimensi spasial, bahwa 3D menunjukkan suatu titik koordinat Cartesian X, Y dan Z. Penggunaan istilah 3D ini dapat digunakan di berbagai bidang dan sering dikaitkan dengan hal-hal lain 
seperti spesifikasi kualitatif tambahan (misalnya: grafis tiga dimensi, 3D video, film 3D, kacamata 3D, suara 3D). Istilah ini biasanya digunakan untuk menunjukkan relevansi jangka waktu tiga dimensi suatu objek, dengan gerakan perspektif untuk menjelaskan sebuah "kedalaman" dari gambar, suara, atau pengalaman taktil. Ketidakjelasan istilah ini menentukan penggunaannya dalam beberapa kasus yang tidak jelas juga yaitu penggunaannya tidak hanya pada contoh-contoh diatas melainkan (sering dalam iklan dan media).

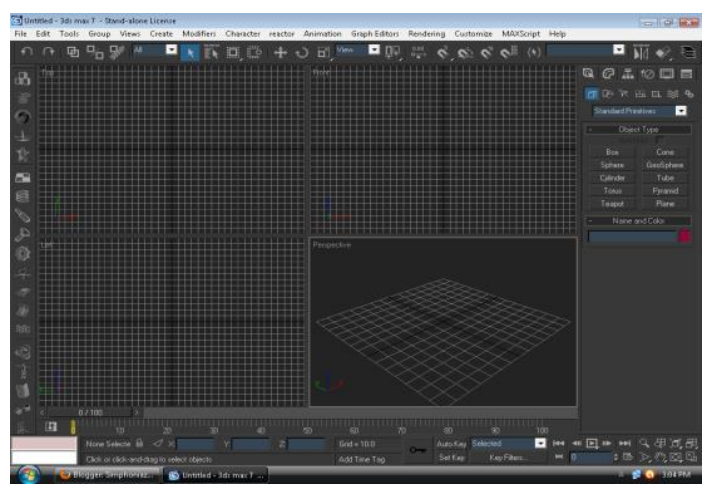

Gambar 1.3D

\section{Definisi Lumion}

Lumion adalah program yang indah, yang memungkinkan kita untuk membuat skenario 3D kita dengan kualitas real-time rendering yang luar biasa. Hal ini juga memungkinkan kita untuk mengimpor objek dan pengaturan dari program lain seperti google sketchup.

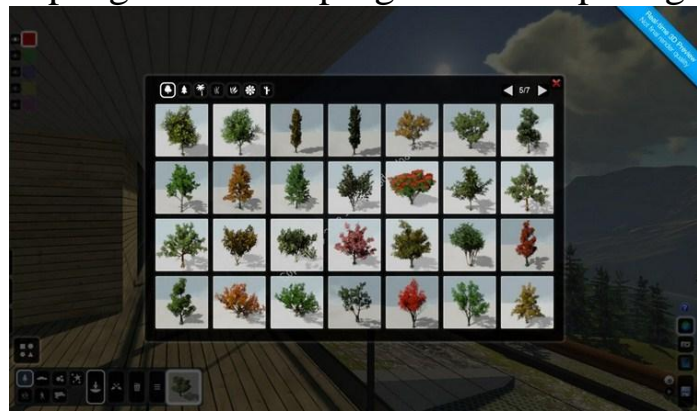

Gambar 2. Lumion

\section{Definisi Photoshop CS3}

Adobe Photoshop CS3 adalah suatu perangkat lunak canggih yang dapat Anda gunakan untuk membuat, menyunting dan memanipulasi tampilan termasuk mengoreksi warna dan memberi efek tampilan atas sebuah gambar atau photo, hasil dari program ini merupakan sebuah gambar / image, di dalam komputer grafis terbagi menjadi 2 kelompok yaitu gambar Bitmap dan gambar Vektor. 


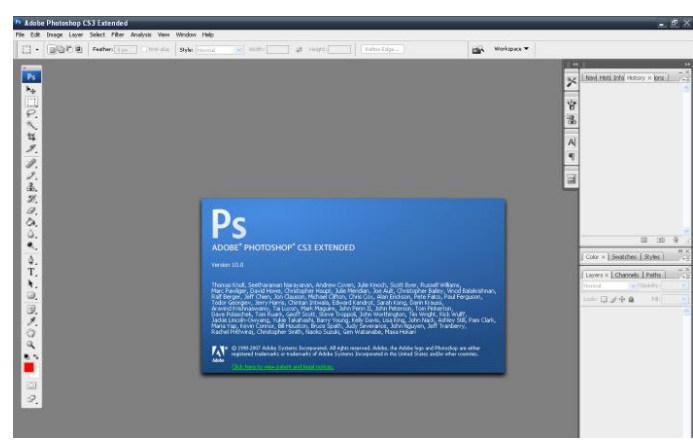

Gambar 3.Photoshop CS3

\section{PEMBAHASAN}

Dalam membuat media animasi desain interior khususnya animasi 3D perlu dilakukan beberapa tahapan konsep produksi media (KPM), diantaranya Preproduction, Production, dan Postproduction.

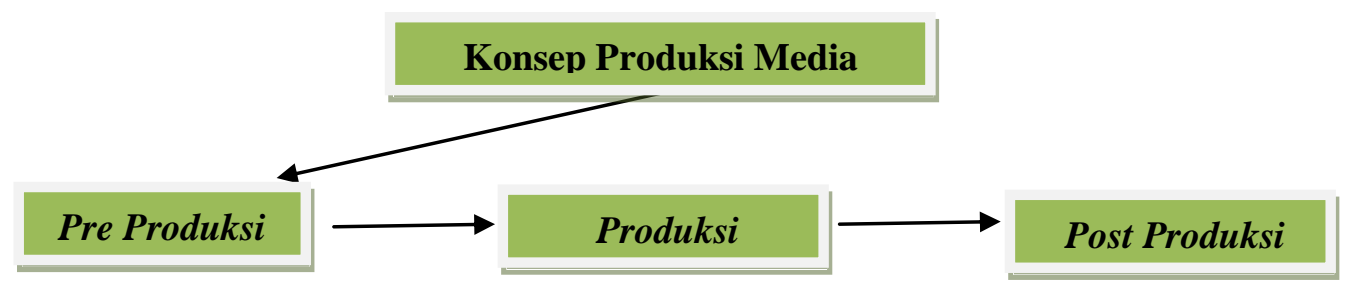

Gambar 4. Konsep Produksi Media

\section{Preproduction}

Ada beberapa langkah Preproduction dalam pembuatan Media animasi 3D video pembelajaran, dimulai dari observasi lapangan dengan mengumpulkan data-data yang diperlukan, kemudian yang dituangkan dalam sebuah ide/gagasan secara sistematis agar menghasilkan pesan dari media video interior itu sampai kepada penonton, lalu diikuti dengan pembuatan sinopsis, Script Writting dan Storyboard.

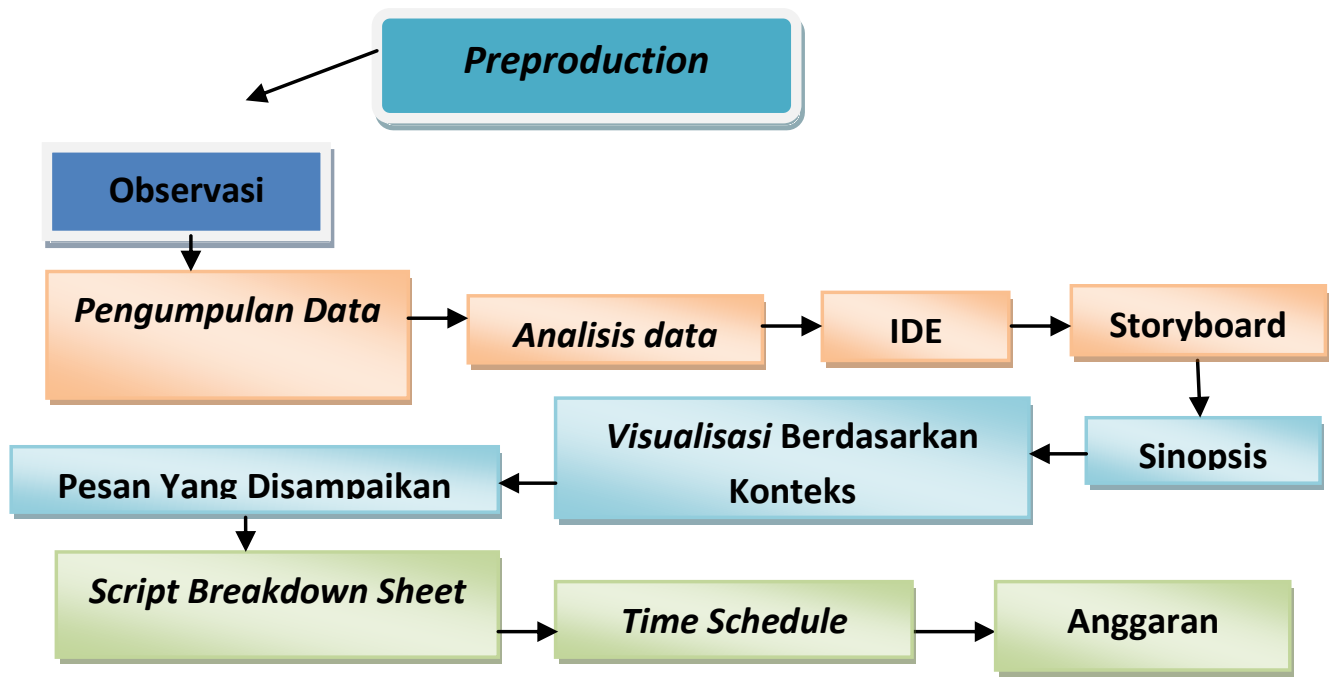

Gambar 5. Preproduction 


\section{Observasi}

Pengamatan yang dilakukan secara khusus pada pembuatan media animasi 3D, mengenai media promosi yang pernah dibuat, beberapa media diantaranya adalah promosi melalui survey langsung ke masyarakat.

\section{Ide}

Video animasi merupakan media yang sangat efektif untuk memberikan informasi dan sekaligus promosi bagi pembuatan media animasi 3D kepada masyarakat luas sebagai salah satu perusahaan bergerak di bidang pembangunan dan jasa. Dengan adanya Media video animasi pembelajaran ini diharapkan masyarakat dapat mengingat 95\% dari apa yang dilihat, didengar dan dialaminya secara bersamaan. Di dalam perkembangannya pembuatan media animasi 3D ingin meningkatkan mutu dan citra pembuatan media animasi 3D khususnya pada masyarakat yang menggemari aplikasi 3D. pembuatan media animasi 3D media yang lebih efektif dan efisien, dari hal tersebut maka menjadi garis besar terciptanya ide untuk merancang Media video animasi pembelajaran informasi dan promosi pada pembuatan media animasi 3D.

\section{Sinopsis}

Pembuatan media animasi 3D memiliki keunggulan dari segi kualitas bahan serta design yang menarik dan pelayanan yang baik. Dari kegiatan-kegiatan pembuatan media animasi 3D membuktikan perusahaan tersebut memiliki kreatifitas dan kualitas yang baik. media video animasi pembelajaran ini dibuat dengan mengambil foto-foto dan design 3 dimensi yang dikemas dan diberi efek-efek sedemikian rupa agar tampilannya lebih menarik.

\section{STORYBOARD}

Storyboard adalah sebuah gambar sket yang dilengkapi dengan petunjuk atau catatan pengambilan gambar sekaligus gerak pada sebuah karakter untuk kebutuhan pembuatan video animasi. Selama proses preproduction, perencanaan yang berhubungan dengan visualiasasi yang akan dibuat membutuhkan storyboard sebagai media bantuannya. Adapun storyboard dalam Video Animasi 3D adalah sebagai berikut :

\section{Scene 1}

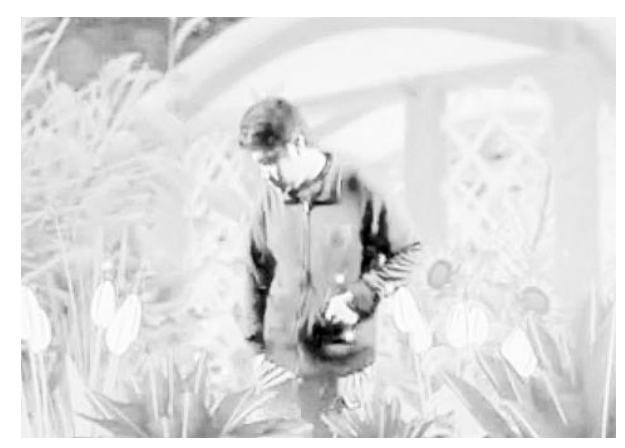

\section{Full Shot (FS)}

Animasi Orang sedang mengambil sesuatu di kantungmya

\section{Gambar 6. Animasi Orang sedang mengambil sesuatu di kantungmya}




\section{Scene 2}

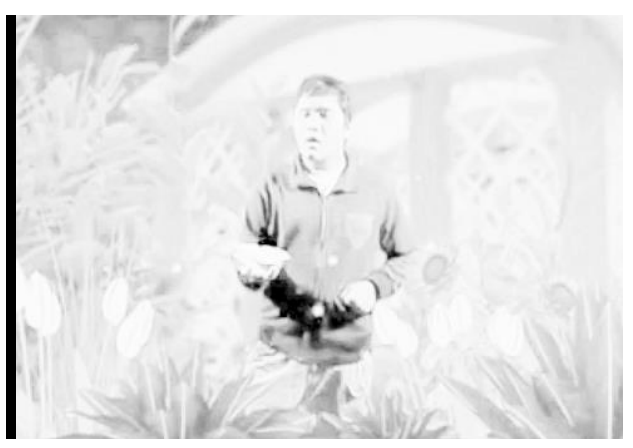

\section{Full Shot (FS)}

Animasi kupu-kupu keluar dari tangan

Gambar 7. Animasi kupu-kupu keluar dari tangan

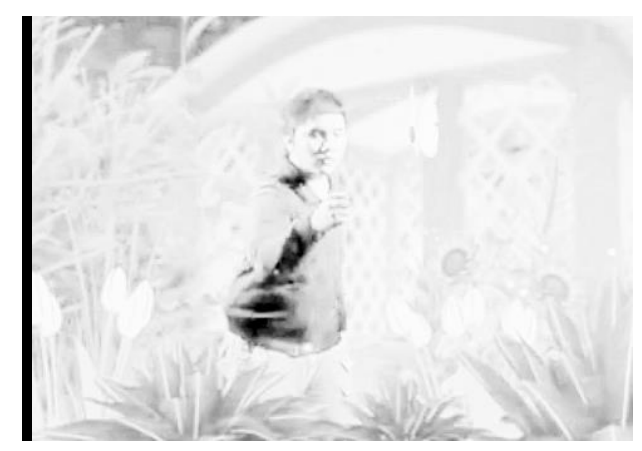

\section{Full Shot (FS)}

Animasi kupu-kupu terbang

\section{Gambar 8. Animasi kupu-kupu terbang}

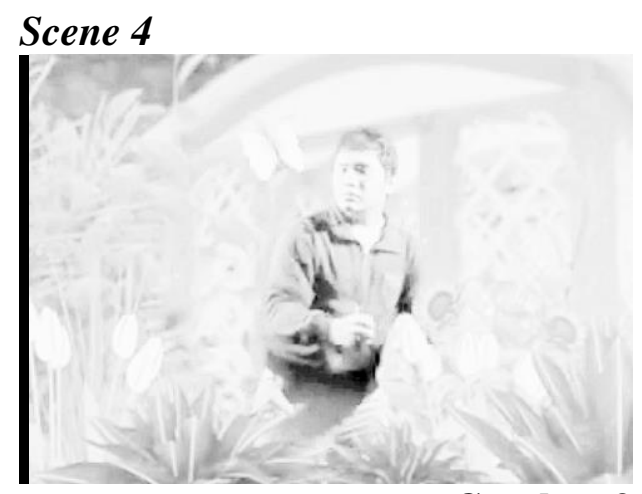

Full Shot (FS)

Animasi kupu-kupu terbang depan orang

\section{Gambar 9. Animasi kupu-kupu terbang} depan orang

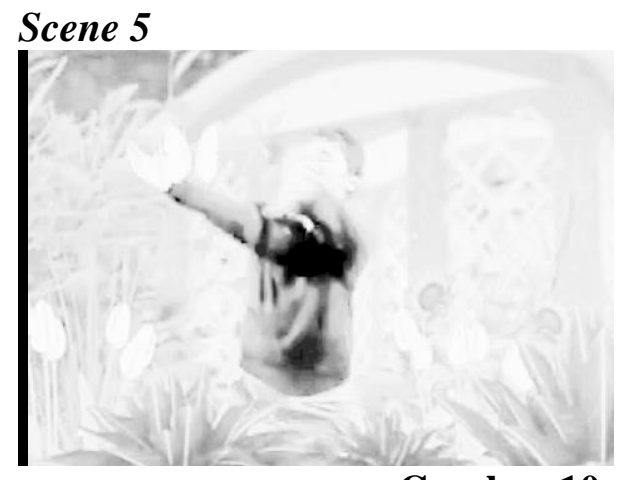

\section{Full Shot (FS) \\ video animasi pada saat tangkap \\ kupu-kupu}

Gambar 10. video animasi pada saat tangkap

kupu-kupu 


\section{Scene 6}

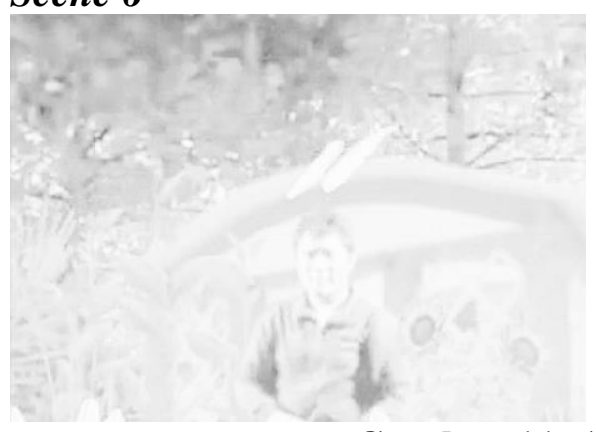

Full Shot (FS)

Animasi Kupu-Kupu Terbang keatas

\section{Gambar 11. Animasi Kupu-Kupu Terbang keatas}

\section{Scene 7}

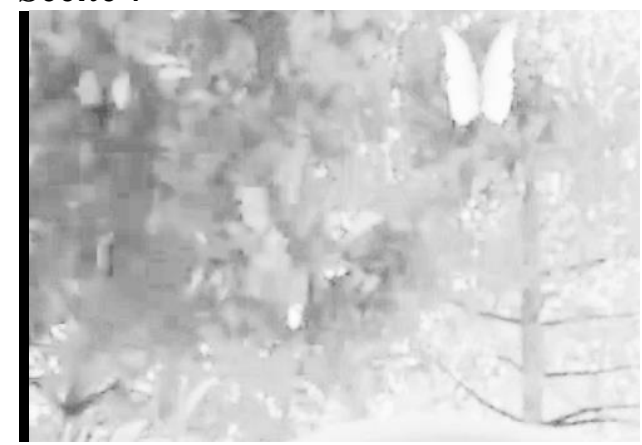

\section{Full Shot (FS)}

Animasi Kupu-Kupu Terbang Terbang melewati objek

\section{Gambar 12. Animasi Kupu-Kupu Terbang melewati objek}

\section{PRODUCTION}

Production adalah proses pengambilan gambar atau shooting video untuk pewujudan rumusan dari tahap preproduction dalam bentuk skenario, naskah, dan storyboard yang telah dibuat. Pada tahap production semua unsur teknis dan kreatif seperti naskah, actor, sinematografi dan suara bergabung dibawah pengawasan kreatif sutradara.

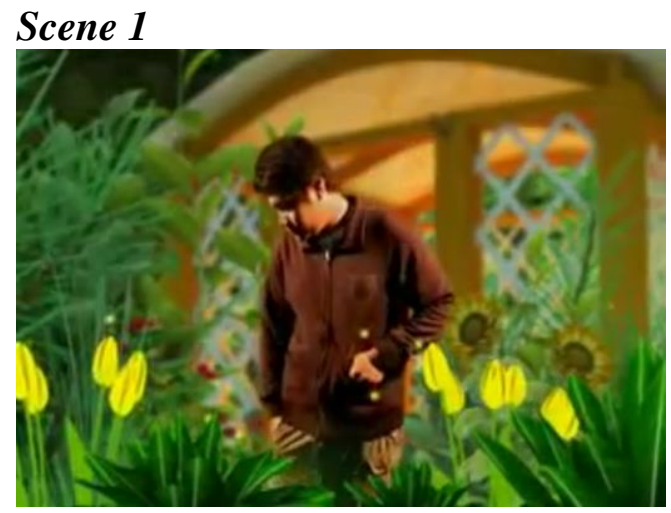

Full Shot (FS)

Animasi Orang sedang mengambil sesuatu di kantungmya

Gambar 13. Animasi Orang sedang mengambil sesuatu di kantungmya 


\section{Scene 2}

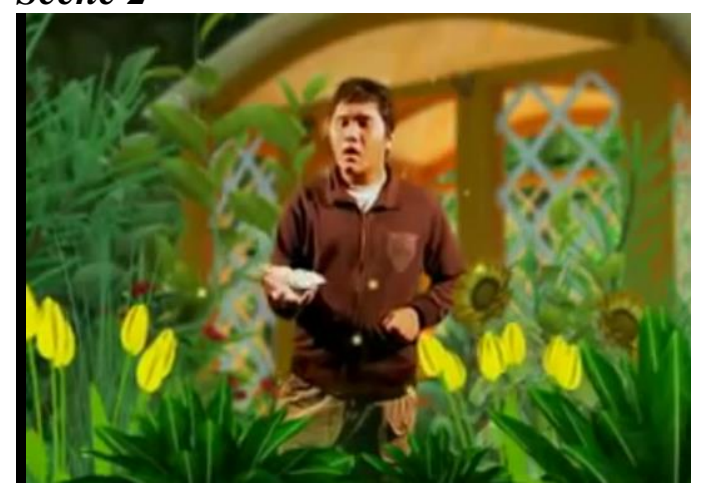

Full Shot (FS)

Animasi kupu-kupu keluar dari tangan

Gambar 14. Animasi kupu-kupu keluar dari tangan

\section{Scene 3}

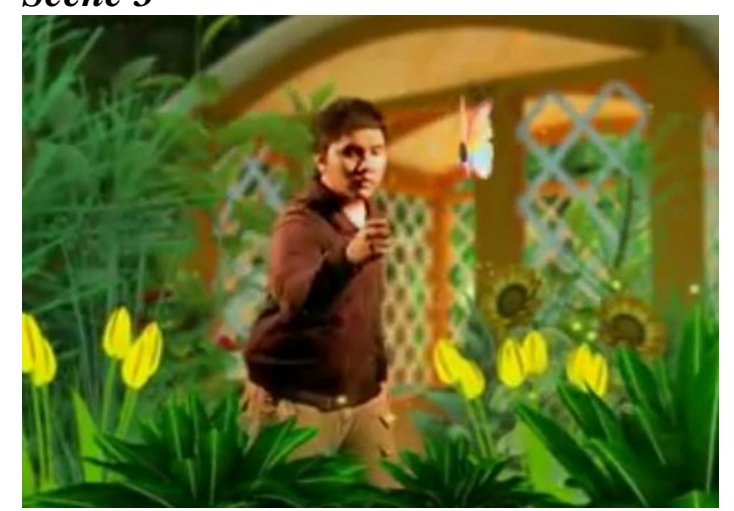

Full Shot (FS)

Animasi kupu-kupu terbang

Gambar 15. Animasi kupu-kupu terbang

\section{Scene 4}

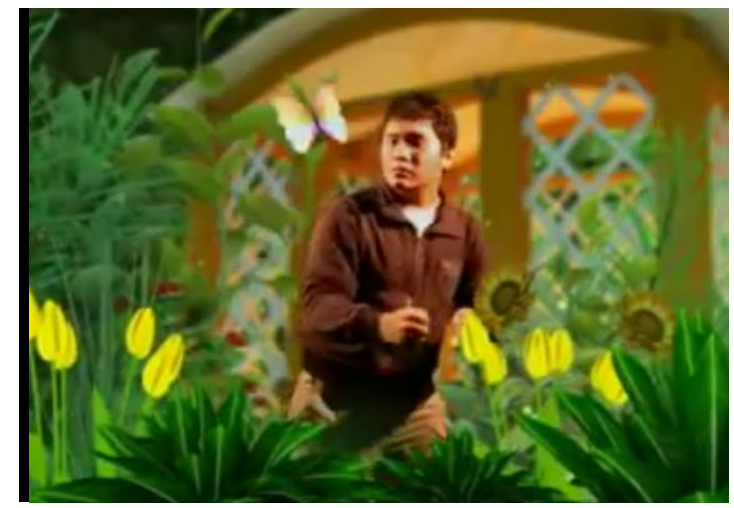

Full Shot (FS)

Animasi kupu-kupu terbang

depan orang

Gambar 16. Animasi kupu-kupu terbang

depan orang 


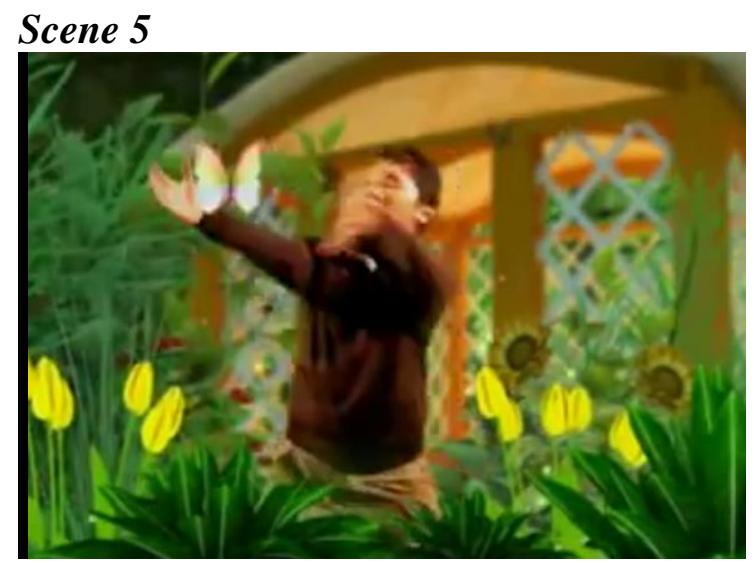

Full Shot (FS)

video animasi pada saat tangkap kupu-kupu

Gambar 17. video animasi pada saat tangkap kupu-kupu

\section{Scene 6}

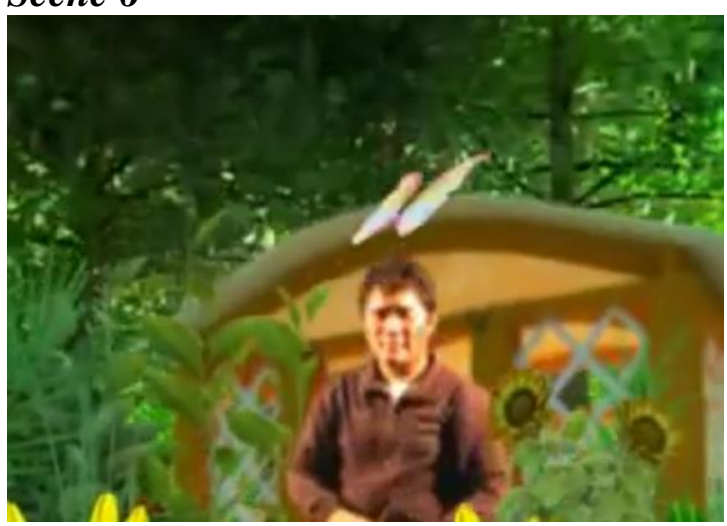

Full Shot (FS)

Animasi Kupu-Kupu Terbang keatas

Gambar 18. Animasi Kupu-Kupu Terbang keatas

\section{Scene 7}

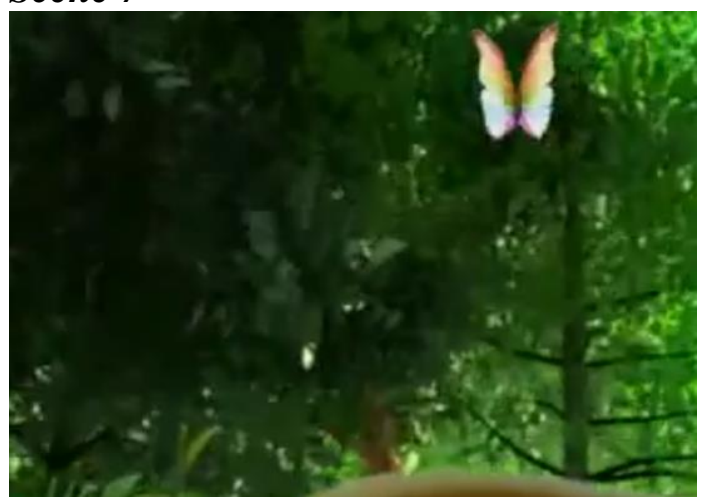

Full Shot (FS)

Animasi Kupu-Kupu Terbang melewati objek

Gambar 19. Animasi Kupu-Kupu Terbang melewati objek 


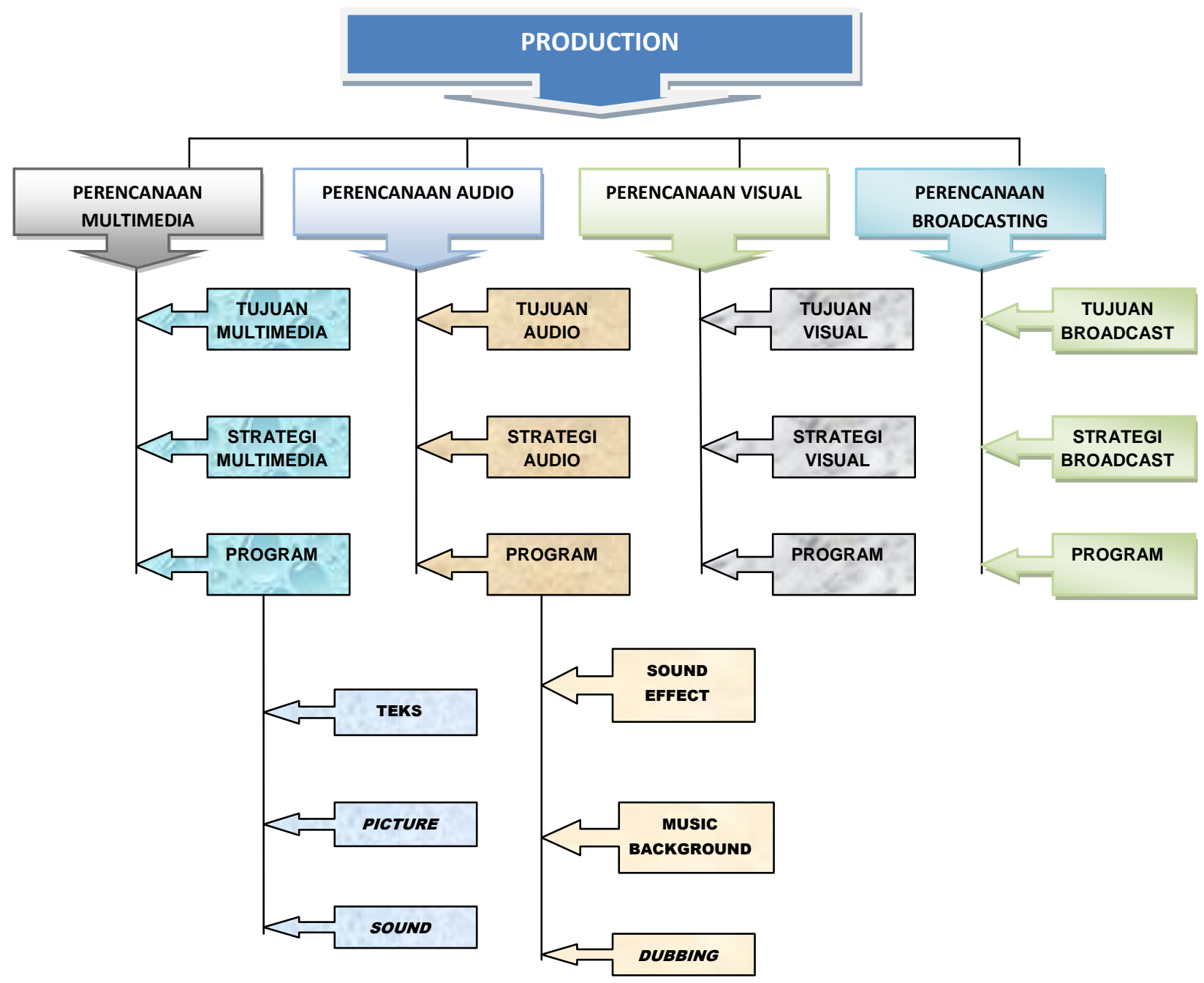

\section{Postproduction}

Gambar 20. Preproduction

Tahap postproduction adalah proses finishing sebuah karya sampai menjadi sebuah video yang utuh dan mampu menyampaikan sebuah cerita atau pesan kepada audience.

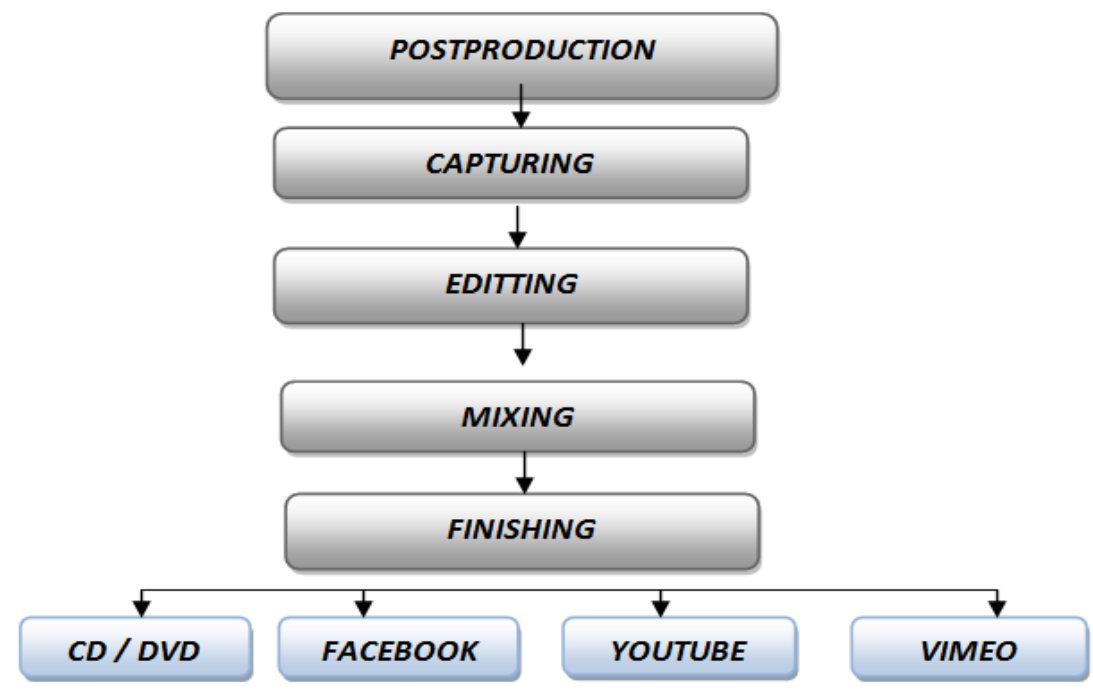

Gambar 21. Preproduction 


\section{LITERATURE REVIEW}

1. Teknologi Media Pembelajaran Sejarah Melalui pemanfaatan Multimedia Animasi Interaktif adalah salah satu jurnal yang di buat oleh Ilham Eka Putra, S.Kom., M.Hum sebagai dosen Sistem Informasi STMIK Indonesia Padang. Penelitian ini menjelaskan tentang kurangnya media publikasi berbentuk Animasi yang berbentuk Teknologi Media Pembelajaran Sejarah Melalui pemanfaatan Multimedia Animasi Interaktif 2013.

2. Pembuatan Film Animasi Pendek "Dahsyatnya Sedekah" Berbasis Multimedia Menggunakan Teknik 2d Hybrid Animation Dengan Pemanfaatan Graphic adalah salah satu jurnal yang di buat oleh Chabib Syafrudin, Wahyu Pujiyono sebagai mahasiswa Universitas Ahmad Dahlan yogyakarta. Penelitian ini menjelaskan tentang kurangnya media publikasi berbentuk film animasi yang berbentuk Dahsyatnya Sedekah.

3. Efektifitas animasi multimedia melalui model pembelajaran kooperatif tipe student team Achievement Division (STAD) terhadap aktivitas belajar dan penguasaan materi pokok sistem peredaran darah oleh siswa (Studi Eksperimen pada Siswa Kelas XI IPA Semester Ganjil SMA Negeri 1 Sumberejo Tahun Pelajaran 2012/2013) adalah salah satu Skripsi yang dibuat oleh Nuris Mukhton sebagai mahasiswa Universitas Lampung.

4. Kemajuan teknologi animasi juga dijadikan sebagai alat bantu dalam menyediakan informasi secara mudah dan efesien, namun dibalik kemajuan teknologi yang ada saat ini dengan banyaknya alat bantu di negara kita sendiri masih banyak orang atau pun industri yang memiliki keterbatasan biaya dan kemampuan dalam penggunaan software animasi atau pun memiliki biaya tapi tidak mampu mengunakan software tersebut, Pemanfaatan software animasi secara efektif dapat dijadikan sebagai salah satu alternatif dalam pembuatan. ANIMASI 3D KISAH AYU INTAN PERMANI JURNAL SKRIPSI Disusun Oleh Apriliana Indah Paramitha STMIK AMIKOM PURWOKERTO.

5. membuat iklan animasi 3D berupa iklan layanan masyarakat yang menarik. Kegiatan yang dilakukan sebelum proses pengerjaan animasi adalah menganalisis kebutuhan pengerjaan dan proses pengerjaan animasi iklan. Tahap pengerjaan terbagi menjadi tiga, yaitu tahap pra produksi yang terbagi menjadi fase ide/cerita, penulisan naskah dan pembuatan storyboard, tahap produksi yang terbagi menjadi fase modeling, texturing, rigging, animasi, lighting dan rendering, serta tahap paska produksi yang terbagi menjadi fase compositing, koreksi warna dan hasil akhir. Fase modeling, animasi dan rendering membutuhkan waktu pengerjaan yang lebih lama dibandingkan dengan fase lainnya. "PERANCANGAN BANGUN PEMBUATAN ANIMASI IKLAN LAYANAN MASYARAKAT "MASA DEPAN TANPA NARKOBA" Budi Setiawan (budicolasetiawan@gmail.com), Alfitransyah (alfitransyah@yahoo.com) Iis Pradesan S.Kom., M.T.(iis.pradesan@gmail.com) Program Studi Teknik Informatika STMIK GI PALEMBANG. 


\section{KESIMPULAN}

Setelah penulis melakukan penelitian pada Video Animasi 3D Sebagai Salah Satu Pembelajaran, penulis berkesimpulan bahwa Media video animasi Desain Interior yang dikemas dalam bentuk Desain video animasi sangat di perlukan bagi Video Animasi 3D Sebagai Salah Satu Pembelajaran, dengan adanya Media video animasi 3D Sebagai Salah Satu Pembelajaran tersebut dapat meningkatkan suatu pembelajaran pembuatan 3DMax.

Dalam pembuatan media Video Animasi 3D Sebagai Salah Satu Pembelajaran yang baik, harus memperhatikan faktor-faktor yang berhubungan dengan Video Animasi 3D Sebagai Salah Satu Pembelajaran. Dalam hal ini penulis menyesuaikan dengan keinginan masyarakat, mulai dari pembuatan Desain, Animasi, tampilan, isi pesan dan penutup. Hal ini bertujuan untuk memperkuat media Desain video Animasi dalam 3D Sebagai Salah Satu Pembelajaran.

\section{DAFTAR PUSTAKA}

[1] Abdul Razaq, 2011 The Magic of Movie Editing, Media Kita, Jakarta,

[2] Alfitransyah, Setiawan Budi Iis Pradesan S.Kom., M.T 2010 "PERANCANGAN BANGUN PEMBUATAN ANIMASI IKLAN LAYANAN MASYARAKAT "MASA DEPAN TANPA NARKOBA" Teknik Informatika STMIK GI Palembang

[3] Apriliana Indah Paramitha 2010 ANIMASI 3D KISAH AYU INTAN PERMANI STMIK Amikom Purwokerto

[4] Atmohoetomo, 2013 Media Iklan dan Periklanan, Jakarta

[5] Ching, 2014 Konsep Dasar Perancangan Interior, Jakarta,

[6] Lukiati Komala, 2010 Media Informasi animasi, Bandung,

[7] Maimunah, Lusyani Sunarya, Nina Larasati. 2012. Media Company Profile Sebagai Sarana Penunjang Informasi dan Promosi. Journal CCIT Vol.5 No.3 - Mei 2012. Tangerang: Perguruan Tinggi Raharja.

[8] Melvy Ayuningtias, 2011 Berkarier di bidang Broadcasting, Media Pressindo, Yogyakarta

[9] Mukhton Nuris, 2012/2013, Efektifitas animasi multimedia melalui model pembelajaran kooperatif tipe student team Achievement Division (STAD) terhadap aktivitas belajar dan penguasaan materi pokok sistem peredaran darah oleh siswa, Universitas Lampung

[10] Pujiyono Wahyu, Syafrudin Chabib, 2011, Pembuatan Film Animasi Pendek "Dahsyatnya Sedekah" Berbasis Multimedia Menggunakan Teknik 2d Hybrid Animation, Universitas Ahmad Dahlan yogyakarta

[11] Putra Eka Ilham S.Kom., M.Hum, 2013 Media publikasi berbentuk Animasi yang berbentuk Teknologi Media Pembelajaran Sejarah Melalui pemanfaatan Multimedia Animasi Interaktif, Sistem Informasi STMIK Indonesia Padang

[12] Suptandar, 2010 Jenis-jenis Media interior desain, Jakarta.

[13] Suyanto, 2014 Media Informasi animasi, Bandung.

[14] Vaughan, 2012 Broadcasting To Be Broadcaster, Yogyakarta, Graha Ilmu.

[15] Yakup, 2013 Media Informasi Manajemen, Media Pressindo, Yogyakarta. 